the possibility of toxins in apparently innocuous foods and medicines.

2. Further toxicological investigations, including analysis for fungal products, and examination of the urine for the fluorescent material described by Curry et al. (1962).

3. Further viral studies by all available techniques.

4. Chemical analysis of the liver and serum lipids, including estimations of serum lipoproteins.

5. Studies on liver enzymes, particularly those concerned with carbohydrate metabolism, preferably on biopsy rather than necropsy material.

6. Estimations during the acute stage of serum levels of adrenal corticoids, insulin, and growth hormone.

\section{Treatment}

Symptomatic treatment was unsuccessful in all Auckland patients. Reye et al. (1963) gained the impression that the use of corticosteroids and the continuous infusion of more than $2.5 \mathrm{~g}$. of glucose hourly gave improved chances of survival. As death appears to result from respiratory failure associated with raised intracranial tension, positive-pressure respiration will usually be indicated and hypothermia may be of value.

\section{Summary}

Since 1959 nine Auckland children have died from the disease first described under the title of "encephalopathy and fatty degeneration of the viscera." The constant features have been an acute severe progressive disturbance of cerebral function, a characteristically diffuse and uniform fatty change in the liver, and cerebral swelling. Prodromal coryza and cough, vomiting, hyperpnoea, leucocytosis, hypóglycaemia, low serum $\mathrm{CO}_{2}$ content, fatty changes in renal tubules, and reactive changes in lymphoid tissues have usually been present.

The late pathological effects are described in one of two atypical cases in which the patient survived the acute illness with residual cerebral damage. Another atypical case had a systemic infection by herpes simplex virus. Viral studies in other patients have been negative.

The aetiology is unknown but the effect of a hepatotoxin is thought to be most likely. Suggestions made for the investigation of future cases include the examination of apparently innocuous foods for hepatotoxins of fungal origin.

Dr. Alice Bush, Dr. R. H. Caughey, Dr. G. T. Fox, and Dr. W. R. Lang kindly gave permission for the publication of details of cases in their care. I wish to thank Dr. R. D. K. Reye, Professor Alex J. Steigman, and Professor M. C. Lancaster for helpful comments on these cases ; Dr. Selwyn Hills and Dr. J. F. Burton, in whose departments viral studies were performed; and Dr. P. J. Scott for estimations of lipoproteins.

\section{REFERENCES}

Brit. med. F., 1965, 1, 1261.

Corlett, K. '(1963). Lancet, 2, 937.

Curry, A. S., Guttman, H. A. N., and Price, D. E. (1962). Ibid., 1, 885. Davidson, C. S. (1964). Nutr. Rev., 22, 97.

Duncan, G. G. (1964). Diseases of Metabolism, 5th ed. Saunders, Phila-

Elliott, R. I. K., Mann, T. P., and Nash, F. W. (1963). Lancet, 2, 882.

Elliott, R. I. K., Mann, T. P., and Nash,

Gillman, J., and Gilbert, C. (1958). Brit. med. F., 1, 57.

Gillman, J., and Gilbert, C. (1964). Lancet, 1, 1280.

Bras, G., and Clearkin, K. P. (1955). W. Indian med. F., 4, 91.

Kahil, M. E., Fred, H. L., Brown, H., and Davis, J. S. (1964). Arch. intern. Med., 113, 63 .

Lancet, 1964, 1, 1090 .

Lewis, G. M., Spencer-Peet, J., and Stewart, K. M. (1963). Arch. Dis. Childh., 38, 40.

Lyon, G., Dodge, P. R., and Adams, R. D. (1961). Brain, 84, 680.

Lyon, G., Dodge, P. R., and Adams, R. D. (1961). Brain, 84, 680 . Callum,

Madhavan, T. V., Tulpule, P. G., and Gopalan, C. (1965). Arch. Path., 79, 466.

Maloney, A. F. J. (1963). Lancet, 2, 1122.

Parr, J., Teree, T. M., and Larner, J. (1965). Pediatrics, 35, 770.

Postgrad. med. F., 1962, 38, 642 .

Rees, K. R., and Shotlander, V. L. (1964). Brit. F. exp. Path., 45, 364.

Reye, R. D. K., and Morgan; G. (1963). Lancet, 2, 1061.

I I and Baral, J. (1963). Ibid., 2, 749.

Sea Bong Chang, M. M., Kader, A., Wick, E. L., and Wogan, G. N. (1963). Science, 142, 1191.

Steiskal, J., and Kluska, V. (1964). Lancet, 1, 615.
Tulpule, P. G., Madhavan, T. V., and Gopalan, C. (1964). Ibid., 1, 962.

Utian, H. L., and Wagner, J. M. (1963). Ibid., 2, 1010

Walton, K. W., and Scott, P. J. (1964). F. clin. Path., 17, 627.

\title{
A Brachiocephalic Vascular Syndrome Associated with Cervical Rib
}

\author{
J. C. DE VILLIERS,* M.D., F.R.C.S.
}

Brit. med. F., 1966, 2, 140-143

Cervical ribs may give rise to neurological or vascular syndromes. Virtually all reports concerning the vascular complications deal with the problem of arterial insufficiency in the upper limb. It is not widely appreciated that thrombosis in the right subclavian artery may extend proximally and give rise to cerebral embolism. This condition was first described by Gould in 1884, but Symonds (1927) was the first to offer the explanation that thrombosis in the right subclavian artery extended proximally to the point of junction of the right common carotid artery, and that portions of clot became detached, forming emboli to the cerebral circulation. In all, eight cases have been described with this syndrome, and details are summarized in the Table.

A similar syndrome associated with a traumatic aneurysm of the axillary artery due to an ununited fracture of the right

* Formerly Senior Registrar in Neurosurgery, Atkinson Morley's Hospltal, London. Present address: clavicle was reported by Yates and Guest (1928). In this patient an embolus into the basilar artery was proved at necropsy. Smith (1941) reported an axillary aneurysm with thrombosis extending proximally, and Wood (1941) described an aneurysm of the innominate artery with thrombosis and embolism giving an identical clinical picture to those cases with cervical rib.

\section{Case Report}

In February 1964 a girl aged 15 was found unconscious next to her bed in the early hours of the morning. She had a left hemiparesis, and was admitted to Atkinson Morley's Hospital for investigation. She had suffered from right-sided headaches associated with nausea and yomiting for one year, and had been in almost continuous pain in the right arm and forearm for about three months. Later she developed pallor of the thumb and index finger and a "bruise" of the skin overlying the right first interosseus space. She had also had a chilblain on the right thumb for about two weeks. 


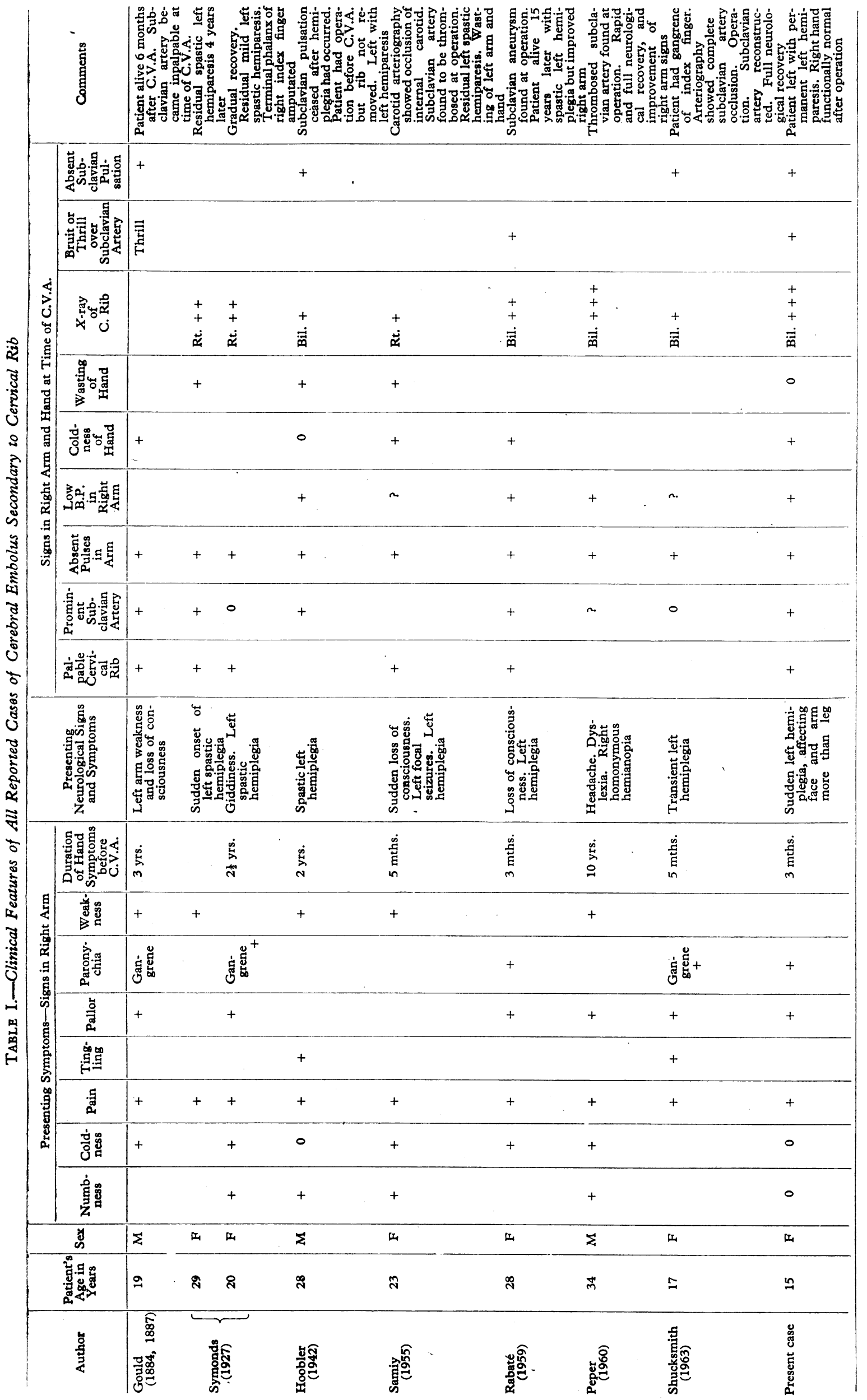


On admission she was found to be drowsy but co-operative and orientated, with a left flaccid hemiparesis affecting the face and arm more than the leg, left-sided sensory impairment, and depression of the reflexes on the left. The fundi were normal. The right brachial and radial pulses were absent, the right subclavian artery was more prominent than normal, and a cervical rib was palpable behind it. There was a soft systolic bruit audible over the right subclavian artery. The blood-pressure was $110 / 80$ in the left arm but could not be obtained cn the right. There was a chronic paronychia of the right thumb and another of the index finger. The white blood count was $13,000 /$ c.mm., with a normal differential, the sedimentation rate was $19 \mathrm{~mm}$. in the first hour, and the serum proteins were $7 \mathrm{~g} . / 100 \mathrm{ml}$.; with a normal albumin-globulin ratio and a normal electrophoretic pattern. Chest $x$-ray films showed bilateral cervical ribs, the one on the right side being larger than the one on the left. Lumbar puncture yielded normal fluid at normal pressure. A right carotid arteriogram showed the features of a middle cerebral artery occlusion (Fig. 1).

At this stage the diagnosis of / cervical rib with subclavian aneurysm, retrograde thrombosis, and middle cerebral artery embolian was made. The patient was therefore referred to Mr. J. Gillespie, under whose care she was admitted to St. George's Hospital. At that stage she had almost full power in the left leg, but there was still marked weakness of the left arm and an indolent ulcer was still present on the right thumb. An aortogram was performed, and this showed a stenosis of the right subclavian artery $0.5 \mathrm{~cm}$. distal to the right cervical rib. The stenotic portion was about half the calibre of the normal segment of the subclavian artery. A post-stenotic dilatation was present and extended into the axilla. There was no evidence of thrombus in the proximal subclavian artery. The other main vessels appeared normal (Fig. 2). The right subclavian aneurysm was explored (Mr. Gillespie). A marked post-stenotic dilatation of the subclavian artery was found, the diameter of this part being quite three times that of the proximal part. An arteriogram done at operation showed the brachial artery to be blocked at its origin. The distal $2 \mathrm{~cm}$. of the cervical rib was resected. The subclavian artery was opened and a very friable vegetation, half an inch $(1.3 \mathrm{~cm}$.) in length and quarter of an inch $(0: 6 \mathrm{~cm}$.) in height, was removed (Fig. 3), and the redundant portion of the dilated subclavian artery plicated in such a way that the part of the artery containing the intimal defect was excluded from the circulation, thus reducing the size of the aneurysm to approximately that of the normal subclavian artery above it. Cervical sympathectomy was then performed. There was an immediate improvement in the right hand, which became warmer; the ulcers on the fingers healed rapidly.

The patient developed a wound infection but otherwise her post-operative course was uneventful. When seen nine months after the operation her main complaint was a clumsiness of the left arm and hand. She had no symptoms referable to the right hand. On examination the pulses in the right arm were found still to be absent from the brachial artery downwards. The blood-pressure could not be obtained in the right arm. The right hand was dry and colder than the left but showed no trophic changes in the fingers. She had a mild left hemiparesis affecting particularly the face and left hand, and there was marked impairment of position sense, and incoordination on the left.

\section{Discussion}

The pathogenesis of the vascular syndrome associated with cervical rib has been fully reviewed by Gunning et al. (1964). The occurrence of cerebral embolism as a complication of the vascular syndrome associated with cervical rib, as described by Symonds in 1927, was the first clear indication that the vascular symptoms in the limbs were also due to emboli. He suggested that mural thrombosis occurred in the subclavian artery as a result of local damage by the cervical rib, and that this thrombus extended backward to the point of junction with the right common carotid artery. A portion of the thrombus could then break off into the common carotid artery. Hoobler (1942) pointed out that the condition could occur only on the right side on account of the common origin of the subclavian and crotid arteries from the innominate artery.

It is easy to understand the process of mural thrombosis extending along the subclavian artery, and a fragment of this thrombus, breaking off as an embolus into the right common carotid artery. In our case, however, there was only a very small vegetation with no evidence of proximal thrombosis extending to the junction of the subclavian with the common carotid. It is a possibility that with certain positions of the arm there would be complete occlusion of the subclavian artery, so that marked turbulence may occur in the proximal part of this vessel. Such positions of the arm will probably be tolerated only during sleep, and it is perhaps significant

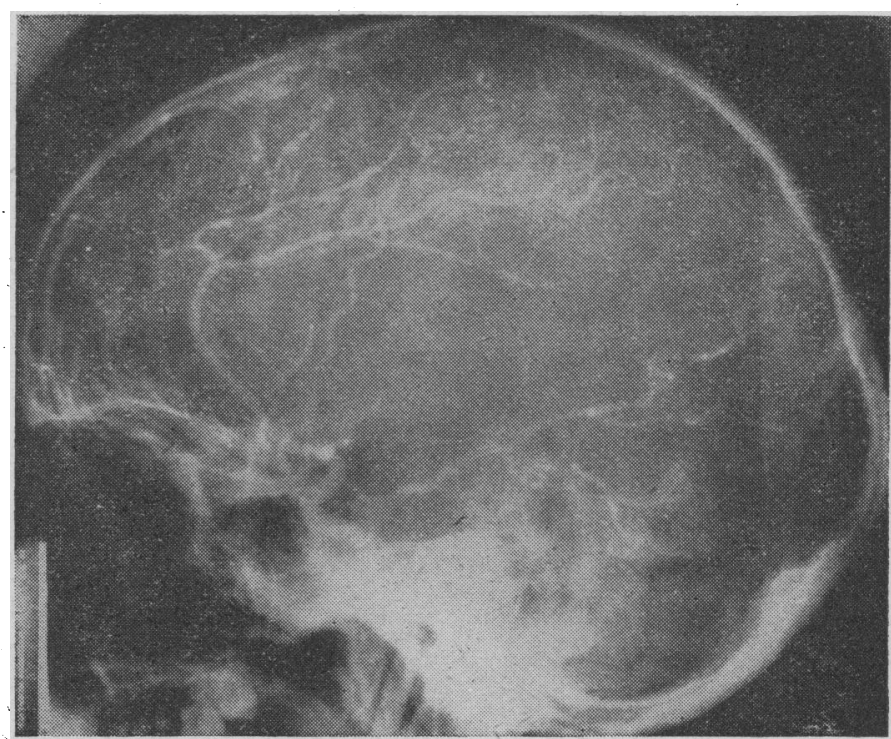

FIG. 1.-Right carotid arteriogram. Middle cerebral artery occlusion.

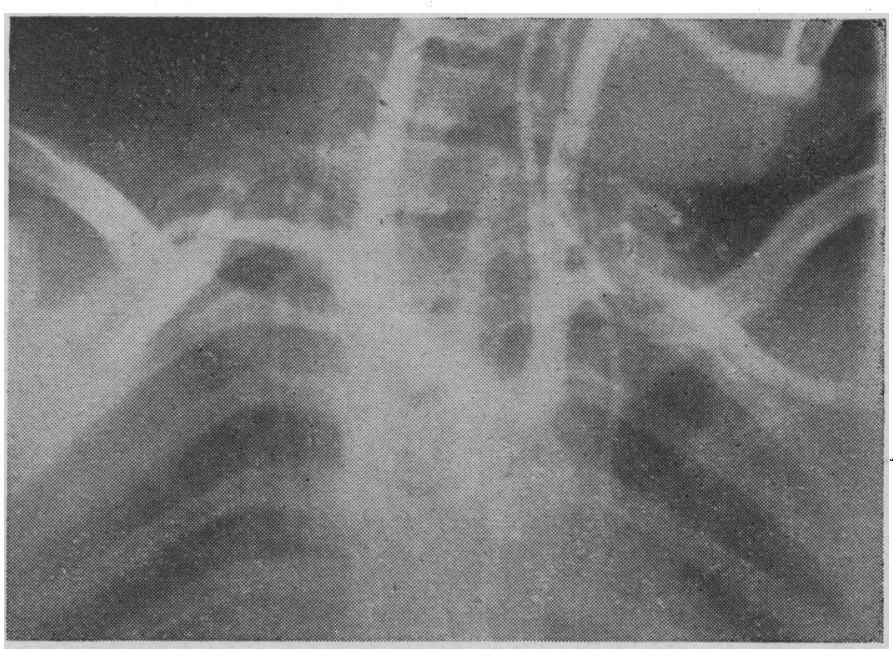

FIG. 2.-Aortogram showing stenosis of right subclavian artęry and poststenotic dilatation.

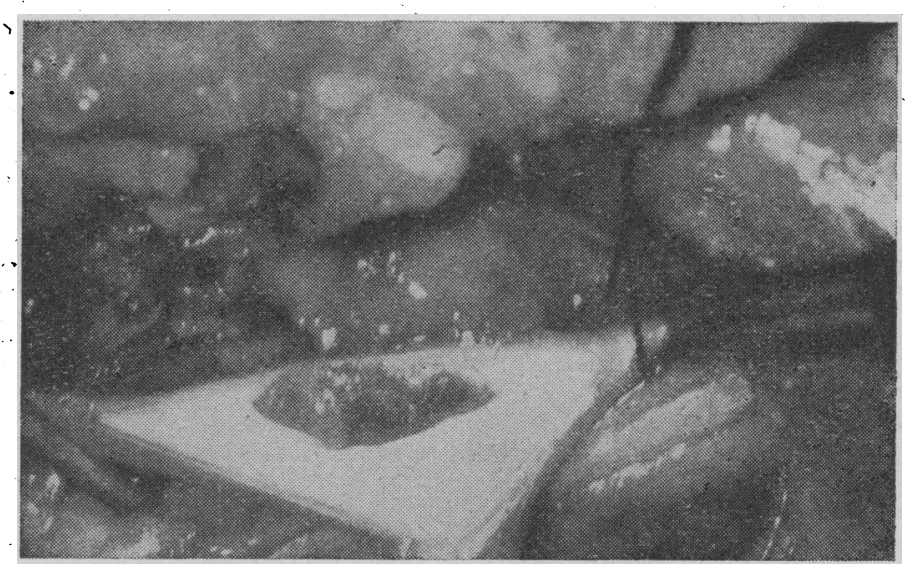

Fig. 3.-Affected segment of artery opened and showing vogetation. 
that four of the patients reported have woken up with the signs of cerebral dysfunction.

\section{Clinical Features}

There is no doubt that this is a rare syndrome, as the vascular complications of cervical rib are uncommon, and aneurysms of the subclavian artery associated with cervical rib are even rarer. Wickham and Martin (1962) could find only 57 examples in the world literature. Schein et al. (1956) collected 29 case reports of thrombosis of the subclavian artery. As cerebral embolism occurs only in association with subclavian aneurysms situated on the right side, this further limits the probability of its occurrence. It is therefore not surprising to find that only eight cases of this condition have been reported so far.

The clinical features are so distinct that the diagnosis can be made with a fair degree of certainty without further investigation. All the patients described with this disease were under the age of 30 except one, and his symptoms started at the age of 24 . Four of the patients were 20 years or younger. Symptoms of vascular insufficiency in the right arm preceded cerebrovascular accident by a period varying from three months to 10 years. The condition must be distinguished from other disease processes which give rise to impairment of the blood supply of the arm associated with cerebrovascular insufficiency. These are included under the broad group of the aortic arch syndromes, and should on account of their own distinctive features not offer any great difficulty (Ross and McKusick, 1953). In general it may be stated that the aortic arch syndromes cause symptoms and signs due to impairment of blood supply to the brain, eye, and face, but that the arms are affected little if at all. This is in marked contrast with the severe vascular changes found in the right arm in the cervical rib vascular syndrome at the time that cerebral symptoms occur.

\section{Treatment}

In their own right vascular symptoms and signs in the arm due to cervical rib should be treated with considerable urgency (Schein et al., 1956 ; Rob and Standeven, 1958). There seems to be a division of opinion on what should be done at operation. Rob and Standeven suggest that removal of the offending cervical rib and upper thoracic ganglionectomy is adequate and should be done as soon as vascular symptoms appear in the hands. They believe that grafting cannot materially improve the outlook when the brachial artery has been blocked by an embolus. Schein et al. (1956) feel that the remaining thrombus in the damaged vessel constitutes a continuing threat to the collateral circulation, and that an endarterectomy should be performed and the affected segment occluded from the circulation to prevent further emboli. Whether the dilated subclavian artery is reconstituted by end-to-end anastomosis after endarterectomy, as described by Eastcott (1962), or whether a graft is used to bridge the gap after excision of the affected segment, as advocated by Wickham and Martin (1962), seems to depend entirely on the conditions present at operation and the choice and experience of the surgeon.
Once there has been embolization from the proximally extending thrombus it would seem rational to explore the artery and remove the thrombus to safeguard the patient against further cerebral emboli. This is a situation where a genuine prophylactic operation for cerebrovascular disease can be performed in the young person who does not have generalized vascular pathology. The patient described by Hoobler (1942) had an exploration of the neck, but the cervical rib was not removed. Sympathectomy was performed and the scalenus anterior was divided, but the artery was not opened. There was complete symptomatic relief for 18 months, but two years after operation the patient suffered a cerebrovascular accident due to an embolus. This perhaps indicates the necessity for a more radical operation, as emphasized by Shucksmith (1963). The fact that cerebral embolism may occur as the result of thrombosis extending proximally in the subclavian artery in patients who suffer from the vascular syndrome secondary to cervical rib should perhaps be an added indication for urgent surgical treatment of this condition. Delay may result in a young patient with a useless right arm and hand due to vascular insufficiency and a paralysed left arm due to cerebral embolism.

\section{Summary}

This is a report of a rare vascular syndrome occurring in young adults with cervical rib. Symptoms of vascular insufficiency occur for a varying period of time in the right arm and are then followed by cerebral embolus, usually in the carotid circulation, with consequent left hemiparesis. The resultant clinical condition is one of left hemiparesis or hemiplegia associated with a right arm showing a varying degree of vascular insufficiency. Early operation is indicated to remove the cervical rib and deal with the damaged subclavian artery to prevent further embolization. A plea is made for early surgical treatment of vascular complications of cervical rib to prevent the occurrence of cerebral embolism.

I would like to thank Mr. Wylie McKissock for his permission to publish the details about his patient, and Mr. J. Gillespie for allowing me to use his operation notes and photographs.

\section{REFERENCES}

Eastcott, H. H. G. (1962). Lancet, 2, 1243.

Gould, A. P. (1884). Trans. clin. Soc. Lond., 17, 95.

- (1887). Ibid., 20, 252.

Gunning, A. J., Pickering, G. W., Robb-Smith, A. H. T., and Russell, R. R. (1964). Quart. F. Med., 33, 133.

Hoobler, S. W. (1942). New Engl. F. Med., 226, 942.

Peper, J. P. H. (1960). Ned T. Geneesk., 104, 332.

Rabaté, M. (1959). Rev. Rheum., 26, 541.

Rob, C. G., and Standeven, A. (1958). Brit. med. \}., 2, 709.

Ross, R. S., and McKusick, V. A. (1953). Arch. intern. Med., 92, 701.

Samiy, E. (1955). F. Neurosurg., 12, 181.

Schein, C. J., Haimovici, H., and Young, H. (1956). Surgery, 40, 428.

Shucksmith, H. S. (1963). Brit. med. f., 2, 835

Smith, G. W. (1941). U.S. nav. med. Bull., 39, 551.

Symonds, C. P. (1927). Brain, 50, 259.

Wickham, J. E. A., and Martin, P. (1962). Brit. f. Surg., 50, 205.

Wood, O. T. (1941). New int. Clin., 1, 18.

Yates, A. G., and Guest, D. (1928). Lancet, 2, 225. 